\title{
Tissue Rebuilding During Spontaneous Regression of Melanoma in the Melanoma-bearing Libechov Minipig
}

\author{
DANIELA PLANSKA ${ }^{1,2,3}$, JANA KOVALSKA ${ }^{3}$, JANA CIZKOVA ${ }^{3,4}$ and VRATISLAV HORAK ${ }^{3}$ \\ ${ }^{1}$ Department of Immunology, Third Faculty of Medicine, Charles University, Prague, Czech Republic; \\ ${ }^{2}$ Faculty of Science, Charles University, Prague, Czech Republic; \\ ${ }^{3}$ Laboratory of Tumour Biology, Institute of Animal Physiology and Genetics AS CR, v.v.i, Libechov, Czech Republic; \\ ${ }^{4}$ Department of Veterinary Sciences, Czech Faculty of Agrobiology, \\ University of Life Sciences, Prague, Czech Republic
}

\begin{abstract}
Background/Aim: Melanoma is a cancer disease with increasing incidence in the Caucasian population. It is often accompanied by spontaneous regression (SR), probably due to high immunogenicity. Understanding of this phenomenon could allow its induction in clinical practice, but detailed study in humans is impossible for ethical reasons. The aim of this study was to determine the role of fibronectin, tenascin C, and MMP-2 in the process of SR. Materials and Methods: Time-lapse study of SR was performed in the MeLiM (Melanoma-bearing Libechov Minipig) model. Skin melanomas were taken from 3 weeks to 8 months of age and immunohistochemically processed for fibronectin, tenascin C and matrix metalloproteinase-2 (MMP-2). Results: Expression of all studied proteins increased up to the 10th week of age. Two structurally different areas were distinguishable from the $3 r d$ month of age. MPP-2 expression predominated in areas with melanoma cells, whereas fibronectin and tenascin-C prevailed in the forming fibrous tissue. Conclusion: Rebuilding of melanoma into the fibrous tissue during SR was connected with a general rise in fibronectin and tenascin $C$ expression.
\end{abstract}

Cutaneous melanoma is a solid tumour derived from activated or genetically altered epidermal melanocytes. The incidence of malignant melanoma increases worldwide in Caucasian population during the last decades. Furthermore, melanoma shows high mortality rate apparently connected with its metastatic ability (1). Melanoma is among the most immunogenic solid cancers, as supported by the phenomenon

Correspondence to: Daniela Plánská, Department of Immunology, Third Faculty of Medicine, Charles University, Ruská 87, 10000 Prague 10, Czech Republic. Tel: +420 728419510, e-mail: PlanskaD@seznam.cz

Key Words: Fibronectin, tenascin C, MMP-2, MeLiM, melanoma, spontaneous regression. of complete and/or partial spontaneous regression (SR) (2). Partial SR of primary cutaneous melanoma is a relatively frequent phenomenon accounting for $10-35 \%$ of all documented cases and is macroscopically manifested as depigmentation around skin tumours. On the contrary, the complete SR is a very rare phenomenon with approximately 40 cases outlined so far (3). Histologically, SR is associated with mass lymphocyte infiltration, melanin aggregation, melanoma cell damage, and melanophage and fibrosis appearance $(4,5)$. The mechanism of SR still remains unexplained. Examination of sequential reactions going on during complete melanoma regression can bring a fundamental shift in the understanding of whole SR process. Subsequently, utilization of ascertained findings could offer new treatment strategies for humans based on inducing/supporting natural regression process. However, time-lapse studies cannot be performed in humans for ethical reasons.

The MeLiM (Melanoma-bearing Libechov Minipig) strain of miniature pigs with hereditary melanoma is a suitable model for melanoma studies due to histopathological (6) and biochemical (7) similarity with human melanoma. This unique animal model allows to investigate the processes of tumour development as well as SR. More than half of MeLiM miniature pigs show multiple nodular cutaneous tumours as well as numerous spleen, lymph node and pulmonary metastases. Approximately $1 / 3$ of the affected piglets die due to melanoma progression during the first two months of age. The remaining $2 / 3$ of animals undergo complete $S R$ which is usually connected with bristle and skin depigmentation (6). These macroscopic changes are accompanied by complete tumour structure rebuilding. The tumour is initially composed almost exclusively of melanoma cells which are gradually destroyed during SR and replaced by fibrous tissue (8). This tissue rebuilding requires a degradation of existing tissue, including its supporting framework of extracellular matrix (ECM), and re-formation of a new one. Previously, ECM has only been considered as an amorphous network supporting 
cells. Nowadays it is known that many biological processes (such as differentiation or gene expression) are regulated by cell-cell and cell-ECM interactions. Moreover, interactions between tumour cells and the surrounding ECM affect tumour growth and metastatic ability $(9,10)$.

ECM is a special extracellular net consisting of collagens, fibrillar glycoproteins, and proteoglycans. In relation to the melanoma, the most frequently discussed potential melanoma markers are fibronectin and tenascin $\mathrm{C}$ together with MMP-2 (matrix metalloproteinase-2, the enzyme degrading ECM components). Fibronectin is an abundant ECM protein forming a network structure pervading the extracellular space (11). It may participate in various processes related to cell adhesion and migration (12). In melanoma, elevated fibronectin levels are associated with invasiveness and metastatic activity of tumours or tumour cell lines (12). Tenascin C, another ECM protein, shows low expression in many tissues of adult mammals $(13,14)$. It has been considered to play an important role in tissue transformation. High levels of tenascin $\mathrm{C}$ are regularly found during wound healing and generally in various tumours (1520). Elevated levels of tenascin $C$ are also found in invasive and metastatic melanomas and melanoma cell lines (similarly to fibronectin) $(21,22)$. ECM degradation is mediated by proteins of the matrix metalloproteinase family. MMP-2 secreted by normal and tumour cells has been shown to play a key role in angiogenesis, tumour cell invasion, and metastasis by promoting degradation of ECM $(23,24)$. In melanoma, a correlation between high MMP-2 expression and low survival rate was observed independently on Clark's levels and Breslow's thickness (25). Thus, all these three proteins - fibronectin, tenascin C, and MMP-2 - are important for melanoma development and might be considered as potential melanoma markers.

The aim of this study was to determine the role of fibronectin, tenascin C, and MMP-2 in the process of SR using the very suitable MeLiM model. Implementation of a time-lapse study (using miniature pigs of different ages) allowed a detail observation of individual SR steps in MeLiM melanoma and searching for mutual relations of studied proteins in the SR process.

\section{Materials and Methods}

Animals and tissue sampling. Fifty eight melanomas of exophytic appearance were taken from the MeLiM miniature pigs at 3 weeks (7 melanomas), 4 weeks ( 8 melanomas), 6 weeks ( 9 melanomas), 8 weeks (6 melanomas), 10 weeks ( 9 melanomas), 3 months ( 7 melanomas), 5 months ( 6 melanomas), and 8 months ( 6 melanomas) of age and used for SR monitoring. The analysed porcine melanomas appeared at birth or developed shortly afterwards. They corresponded to the Clark $\mathrm{V}$ stage used for human melanoma classification. A clear vertical growth of all analysed melanomas was observed. The melanoma cells were found in the reticular layer of dermis and in subcutaneous adipose tissue. Twenty skin samples from healthy (tumour-free) MeLiM animals of equivalent ages were collected for comparison.

Tumours and skin samples were excised under total anaesthesia [premedication with i.m. Atropine $(0.5 \mathrm{mg} / \mathrm{minipig}$; HoechstBiotika, Martin, Slovak Republic) and Stresnil (1 mg/kg of body weight; Janssen Pharmaceutica N.V., Beerse, Belgium) followed with Narcotan inhalation (Leciva, Prague, Czech Republic)]. The wound was closed by individual stitches, and Vetalgin $(0.5 \mathrm{mg} / \mathrm{kg}$ of body weight; Intervet International, Unterschleißheim, Germany) was applied i.m. after the surgery was finished and two days thereafter to control pain after tissue excision and wound suturing. These procedures were performed in accordance with the rules of the European Convention for the Care and Use of Laboratory Animals and on the basis of the Project of Experiment for ensuring the welfare of experimental animals that was assessed and recommended by the Expert Committee of the IAPG AS CR, v.v.i. (Libechov, Czech Republic) and approved by the Expert Committee of the Academy of Sciences of the Czech Republic.

Tissue samples (around $5 \times 5 \mathrm{~mm}$ ) were taken from melanomas immediately after excision, placed on a piece of cork, covered with Jung Tissue Freezing Medium (Leica Microsystems, Wetzlar, Germany) and frozen in liquid nitrogen. Serial cryosections of $6 \mu \mathrm{m}$ thickness were prepared by the Leica CM 1850-Cryostat (Leica, Nussloch, Germany), air dried for $15 \mathrm{~min}$ and stored until use at $-20^{\circ} \mathrm{C}$.

Immunohistochemistry. Melanoma cryosections were processed for detection of fibronectin, tenascin C, and MMP-2 by indirect immunofluorescence. Cryosections were fixed with cold acetone (10 min), washed with PBS (3 times, 5 min each), blocked with $10 \%$ porcine serum in PBS $(1 \mathrm{~h})$, and incubated with primary mouse monoclonal anti-fibronectin antibody (Cat. No. ab6328, dilution 1:100, Abcam, Cambridge, UK), mouse monoclonal anti-MMP-2 antibody (Cat. No. MAB3308, dilution 1:2,000, Chemicon International, Temecula, CA, USA) or goat polyclonal anti-tenascin C antibody (Cat. No. sc-9872, dilution 1:250, Santa Cruz Biotechnology, Dallas, TX, USA) overnight in refrigerator. After washing with PBS (3 times, 5 min each), sections were incubated with appropriate secondary antibody (goat anti-mouse immunoglobulins, Cy3 conjugated, Cat. No. AP124C; rabbit anti-goat immunoglobulins, Cy3 conjugated, Cat. No. AP106C; both diluted 1:1000; Chemicon International) in dark for $1 \mathrm{~h}$. The stained sections were washed with PBS (3 times, 5 min each) and nuclei were counterstained with DAPI (4', 6-diamidino-2-phenylindole, SigmaAldrich, Darmstadt, Germany) (10 min). After final washing in PBS and distilled water, the sections were embedded in the Mounting Medium (prepared according to the technical data sheet No. 777; Polysciences, Inc., Warrington, FL, USA) with Mowiol 4-88 (Calbiochem, San Diego, CA, USA) and n-propyl gallate $(5 \mathrm{mg} / \mathrm{ml}$ final concentration; Sigma-Aldrich, Darmstadt, Germany). Both the primary and secondary antibodies were diluted with the blocking reagent (10\% porcine serum in PBS). Cryosections with omitted primary antibody served as controls. Immunostaining was evaluated using an AX70 fluorescence microscope (Olympus, Tokyo, Japan). Black and white images of detected proteins plus nuclei (DAPI) staining were taken with the DP30BW Monochrome Microscopy Camera (Olympus, Tokyo, Japan). In addition, the tumour areas evaluated by immunohistochemistry were simultaneously monitored by bright-field microscopy to detect the distribution and morphology 

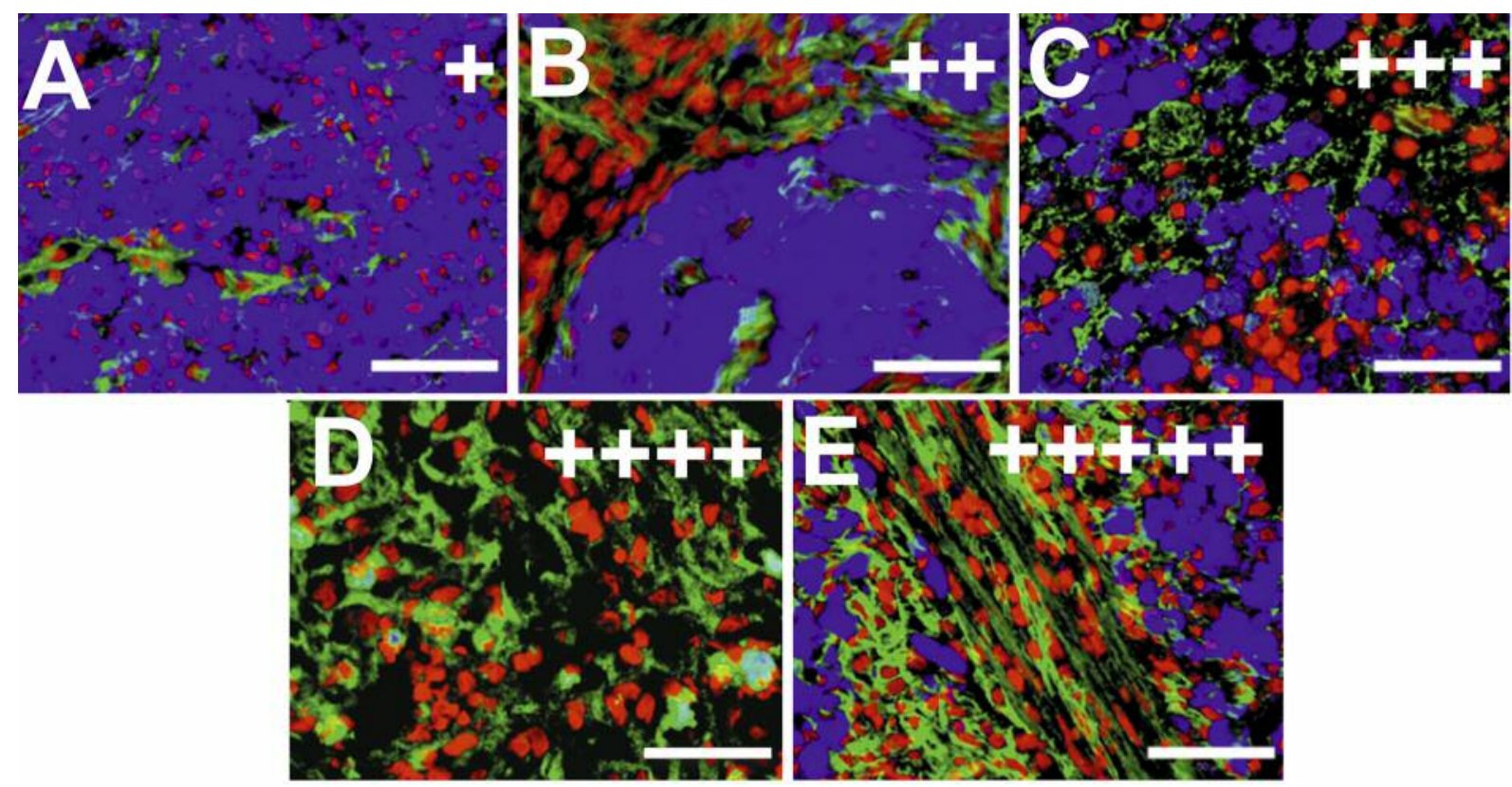

Figure 1. Evaluation of indirect immunofluorescence staining: (A) very low $(+),(B)$ low $(++),(C)$ moderate $(+++),(D)$ high $(++++),(E)$ and very high $(+++++)$; (green - studied protein, blue - melanin, red - nuclei. Original magnification, $\times 200$. Scale bar $=50 \mu m)$.

of melanoma cells. Both immunohistochemical and bright-field microscopy images were pseudo-coloured and overlapped using Micro Image software (Olympus, Tokyo, Japan).

Evaluation of immunohistochemical staining. Expression of the monitored proteins was evaluated on the base of intensity of immunohistochemical staining in extracellular spaces of melanoma tissue. Expression was assigned as very low $(+)$, low $(++)$, moderate $(+++)$, high $(++++)$, and very high $(+++++)$ (Figure 1). Reaction of these proteins in sebum glands, walls of blood vessels, and connective sheaths of bristles were not taken into account for this evaluation.

\section{Results}

Fibronectin. Very low expression of fibronectin was detected in melanomas of 3-week-old pigs (Figure 2A). Thin weakly branched fibres of fibronectin penetrated the tumour. A slight increase in expression of fibronectin and elongation of fibronectin fibres was observed in melanomas of 4-week-old pigs. However, the overall expression in melanoma samples was still evaluated as very low. A gradual increase in fibronectin expression was detected in melanomas of 6-, 8and 10-week-old pigs (Figure 2B). Despite this fact, the overall expression was still classified as low. The 3rd month of age was characterized by proceeding SR which was accompanied by an enlargement of the fibrous tissue. Thus, two histologically different tissue areas (scattered across the melanoma cryosections) were clearly distinguishable starting from this age. Areas still containing melanoma cells were disappearing with gradual age (3, 5, and 8 month) and replaced by the fibrous tissue areas (without melanoma cells) as already described (8). Melanomas of 3- and 5-month-old pigs were characterized by continuous increase in overall expression of fibronectin (throughout the entire melanoma samples) that was classified as medium. However, clear differences in expression were detected between the two tissue areas. The areas with melanoma cells showed low expression of fibronectin in melanomas of 3-month-old-pigs and very low expression (bordering with undetectable level) in melanomas of 5-month-old-pigs. On the contrary, fibronectin expression in the fibrous tissue was very high and it was detected in nearly $4 / 5$ of extracellular spaces in both age groups (Figure 2C). The overall expression of fibronectin in melanomas taken from 8-month-old-pigs increased further to a high level. This rise was apparently caused by continuous enlargement of the fibrous tissue areas which showed very high fibronectin expression as in the previous age groups. The tumour areas still composed of melanoma cells demonstrated again very low to nearly no fibronectin expression (Figure 2D).

Tenascin C. Very low fibrillar expression of tenascin $\mathrm{C}$ was observed in melanomas of 3-week-old pigs (Figure $3 \mathrm{~A}$ ). Tenascin $\mathrm{C}$ formed short wavy fibres which occurred around melanoma cells. A slow gradual rise of tenascin $\mathrm{C}$ expression was detected in melanomas from 4- to 8-week-old pigs and 


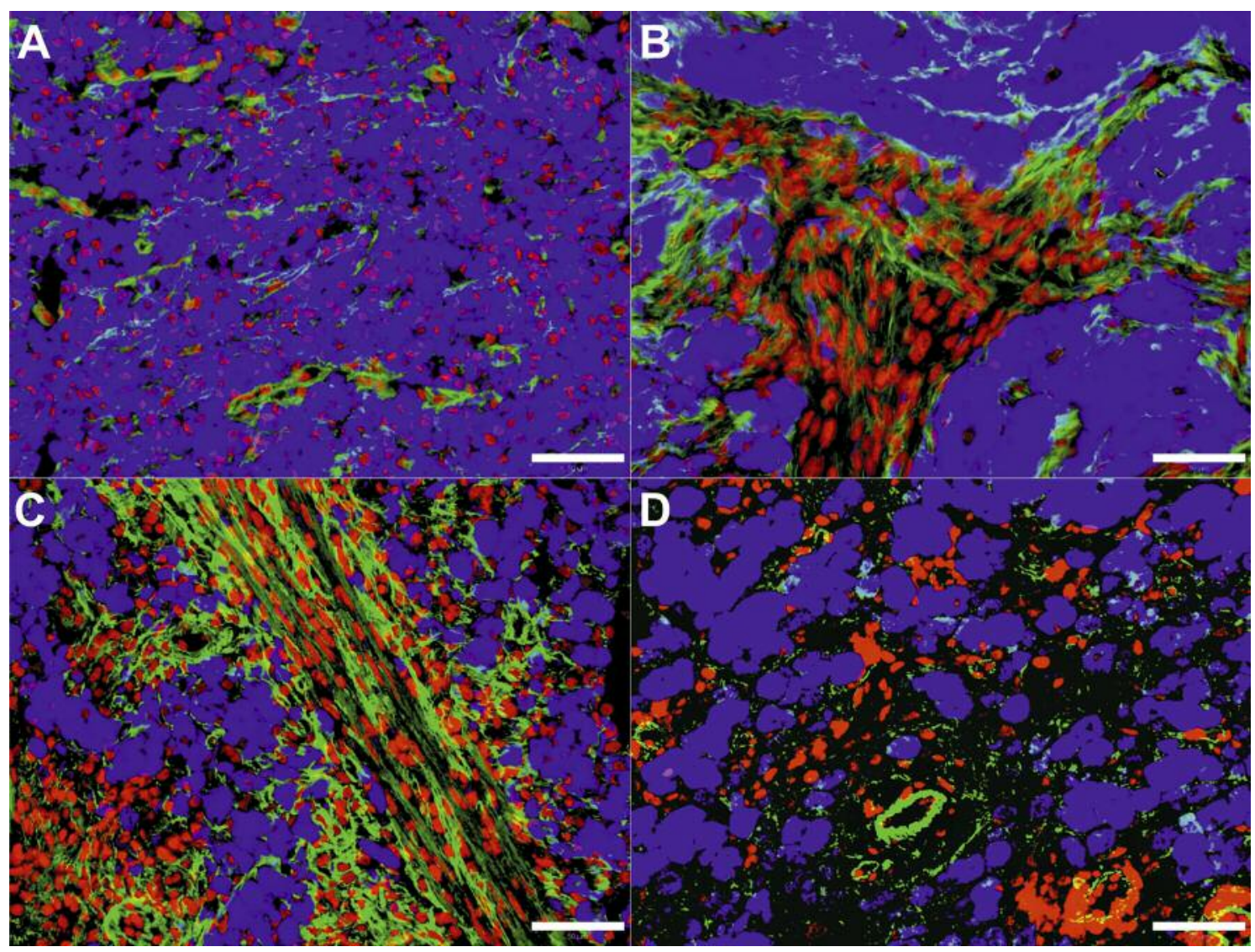

Figure 2. Indirect immunofluorescence staining of fibronectin in swine melanoma: (A) very low expression of weakly branched fibres in 3-week-old pig; (B) low expression of complex networks in 10-week-old pig; $(C)$ very low expression in melanoma cell area compared to very high expression in fibrous tissue area in 5-month-old pig; (D) very low expression in melanoma cell area in 8-month-old pig; (green-fibronectin, blue - melanin, red - nuclei. Original magnification, $\times 200$. Scale bar $=50 \mu \mathrm{m})$.

its sudden rise was observed at the age of 10 weeks. This resulted in extension of tenascin $\mathrm{C}$ fibres and low overall expression (Figure 3B) that was detected also in melanomas of 3-month-old pigs. Areas with melanoma cells showed very low expression of tenascin $\mathrm{C}$ bordering with its undetectable level. On the contrary, a high network-forming expression filling up to half of extracellular spaces was detected in the areas of fibrous tissue. Similar staining pattern with slight increase in overall expression were observed in melanomas of 5- and 8-month-old pigs (Figure 3C and D).

$M M P-2$. Very low granular expression of MMP-2 was detected in melanomas taken from 3-week-old pigs (Figure 4A). It was diffusely distributed in tumour tissue. The melanomas excised from 4-, 6-, 8-, and 10-week-old pigs showed gradual increase in the expression of MMP-2 (Figure 4B) but it was still evaluated as very low. Overall very low expression of MMP-2 was also detected in melanomas of 3- and 5-month-old pigs (Figure 4C) with a small difference between areas with melanoma cells (low expression) and those with the fibrous tissue (very low expression bordering with undetectable). Melanomas of 8-month-old pigs revealed overall low expression of MMP-2. The areas with melanoma cells were characterized by a further slight increase in the MMP-2 expression to medium level (Figure 4D) filling around $1 / 3$ of extracellular spaces. On the other hand, expression in the fibrous tissue areas was still very low or almost none.

Immunohistochemical staining of swine skin. The control skin samples taken from pigs of different ages showed localization of fibronectin, tenascin C and MMP-2 in the epidermis, the sebum glands, walls of blood vessels, and connective sheaths of bristles (not shown). Expression of all these proteins increased with the age of pigs corresponding to the growth and development of these structures. The same results were found also in the analysed melanomas. Overall fibronectin 


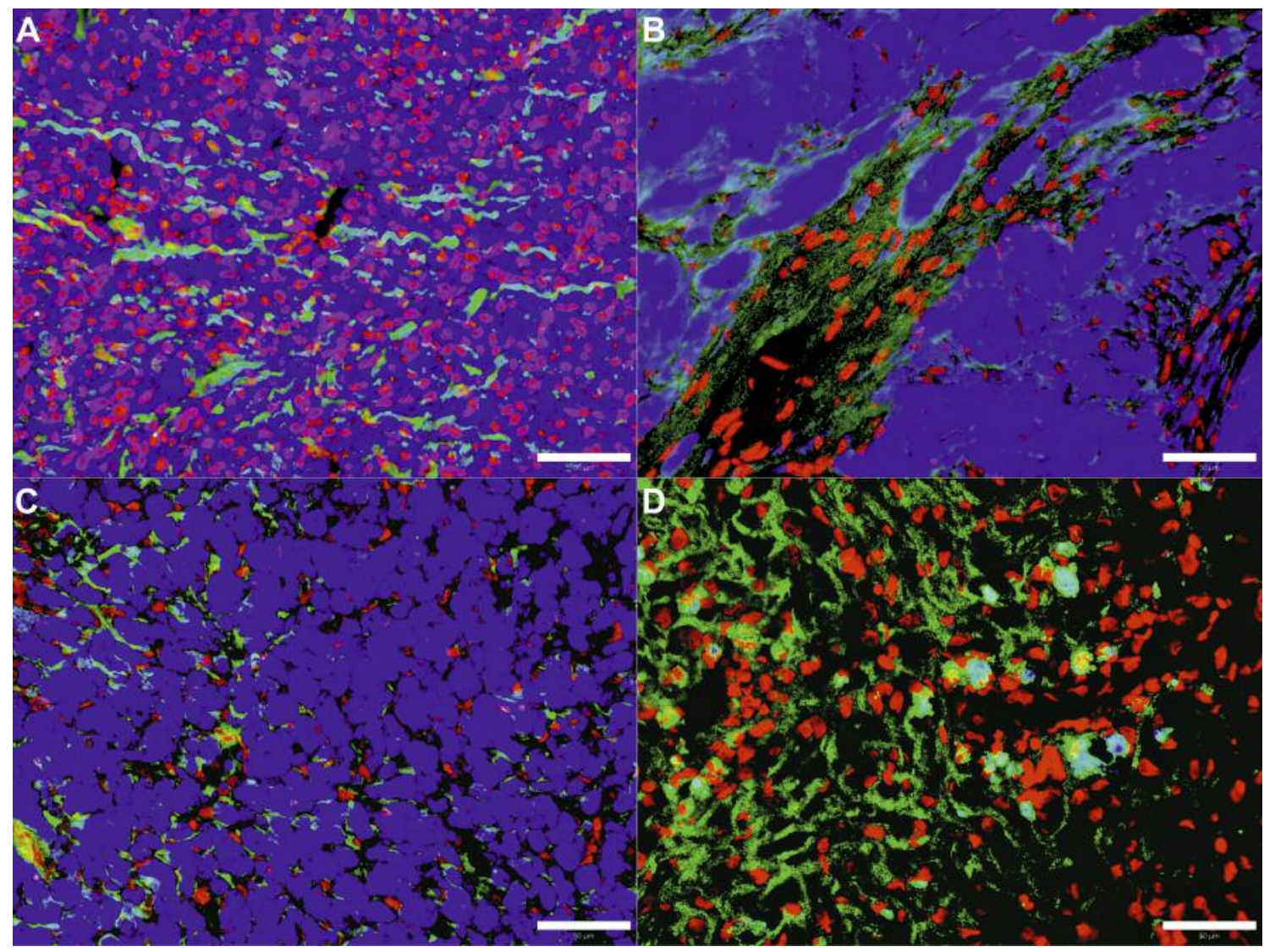

Figure 3. Indirect immunofluorescence staining of tenascin C in swine melanoma: (A) very low fibrous expression in 3-week-old pig; (B) low expression in 10-week-old pig; $(C)$ very low expression in melanoma cell area in 5-month-old pig; $(D)$ high expression of tenascin $C$ networks in fibrous tissue area in 8-month-old pig; (green-tenascin C, blue - melanin, red-nuclei. Original magnification, $\times 200$. Scale bar=50 $\mu$ m).

expression in the skin was weaker compared to higher expression of tenascin $\mathrm{C}$ and MMP-2 in the melanomas of equivalent age.

\section{Discussion}

It has been proved that ECM is not only a skeleton of tissue to which the cells are attached to but its composition is associated with cell signalling and cell phenotype $(9,10,26)$ Further, ECM proteins and enzymes involved in ECM degradation such as fibronectin, tenascin C, and MMP-2 are considered as possible markers of melanoma progression and its elevated levels are associated with poor prognosis of the disease (22, 27-29). A study of tumour tissue ECM dynamics which reflects its synthesis (fibronectin and tenascin $\mathrm{C}$ ) and degradation (MMP-2) is an integral part in understanding melanoma. The aim of this study was to examine these proteins during SR of MeLiM melanoma. Such study focused on their detailed time-lapse observation has not been performed yet. Only expression of tenascin $\mathrm{C}$ and tenascin $\mathrm{X}$ at molecular and immunohistochemical levels in few randomly chosen MeLiM melanomas has been published (30). Recently, the course of SR in this animal model was partially characterized. It was found that this process involves significant destruction of whole skin tumours and their rebuilding into fibrous tissue. It is accompanied by considerable reorganization of essential proteins of the basal lamina - laminin and collagen IV (8).

MeLiM miniature pigs developing multiple skin tumours at birth or shortly thereafter and undergoing their complete SR were used for this study. Thus, tumour development corresponds with the date of animal birth and the course of SR can be related to the actual animal age. Detailed observation at various ages of experimental animals allowed us to study the whole process of SR from the beginning to its late phases which are often accompanied by strong depigmentation of the skin and bristles $(6,8)$. An initial analysis was carried out in the 3rd week of age. A very low 


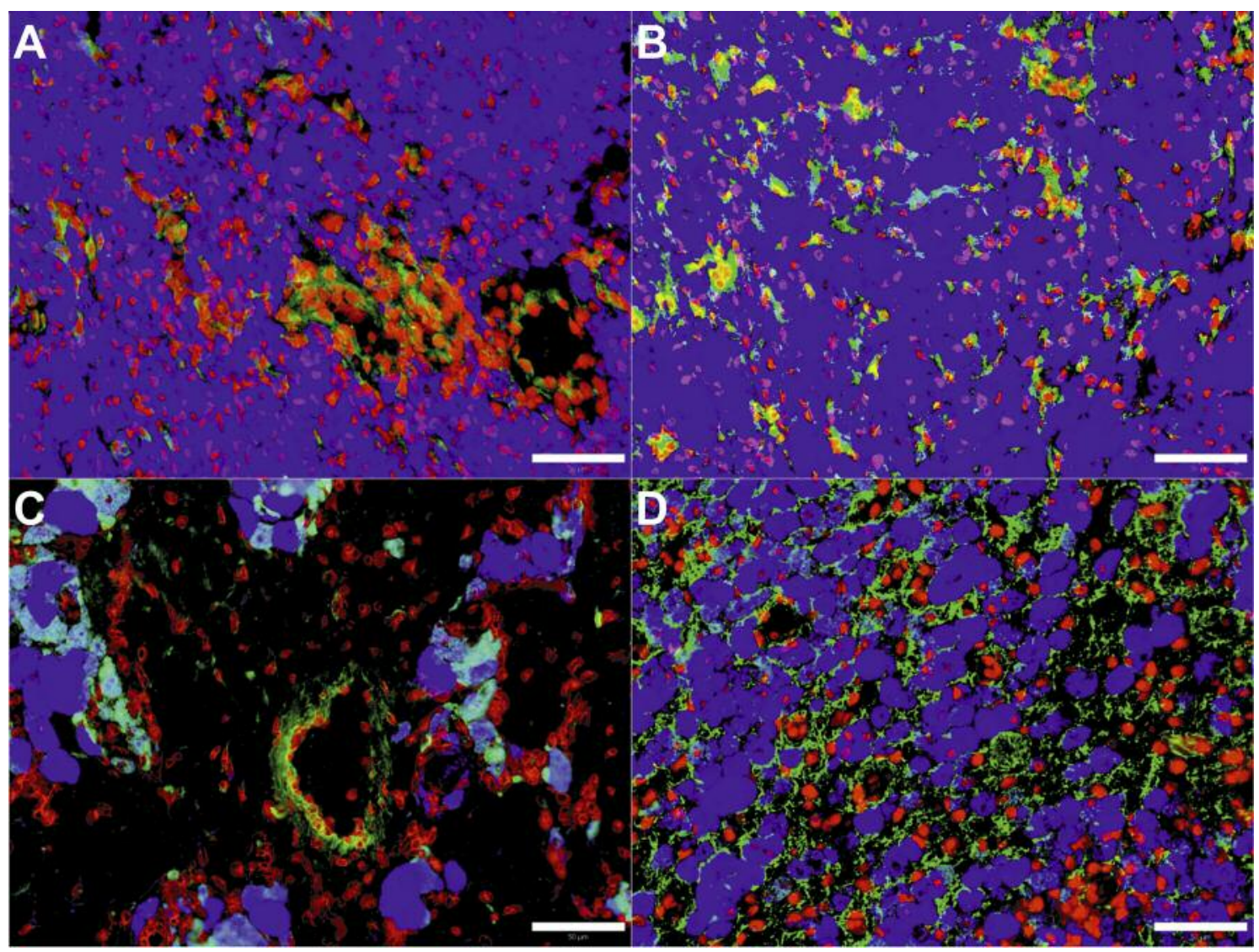

Figure 4. Indirect immunofluorescence staining of MMP-2 in swine melanoma: (A) very low granular expression in 3-week-old pig; (B) very low granular expression in 10-week-old pig; (C) very low granular expression in fibrous tissue area in 5-month-old pig; (D) medium expression in melanoma cells area in 8-month-old pig; (green-MMP-2, blue - melanin, red-nuclei. Original magnification, $\times 200$. Scale bar $=50 \mu m)$.

expression of all monitored proteins was found in this developmental stage followed with slight increases at the 4th and 6th week of age. The expression of MMP-2 was granular and diffusely spread in the tumour, suggesting a slight continuous rebuilding of the entire tissue. Conversely, tenascin $\mathrm{C}$ formed short fibres and fibronectin showed slightly branched fibres. Local fibrous expression of fibronectin could be related to metastatic activity of MeLiM melanoma, as was already described in human melanoma (28). In the process of SR in MeLiM model, we would expect a gradual decline of studied protein expression connected with the destruction of tumour cells (supporting its role as potential melanoma markers). By contrast, continued slight increase in fibronectin level was detected in the successive developing stages and an unforeseen jump in the tenascin $\mathrm{C}$ expression at the 10th week of age was observed. It is known that tenascin $\mathrm{C}$ is largely participating in the healing process $(16,31)$. Thus, the jump in the level of tenascin $\mathrm{C}$ at the 10th week of age could be caused by recognition and destruction of tumour tissue by the immune system $(2,4)$ followed by intensive healing. The mentioned observation is in concordance with the results of a study focused on expression of the basal lamina proteins - collagen IV and laminin - in the MeLiM melanoma (8). It also revealed a significant change in the expression of these two ECM proteins at the 10th week of age (8). For this reason and because of the similar conclusion in the melanomabearing Sinclair swine (32), we consider the 10th week of age as a crucial turning point during SR of porcine melanoma that separates the initial tumour growth phase from the subsequent regression phase.

The other analysed developmental stages $(3,5$ and 8 months of age) showed strong remodelling of melanoma tissue. Continuing destruction of melanoma cells and enlargement of the fibrous tissue was observed. Finally, two histologically distinct areas - still containing melanoma cells and without melanoma cells (the fibrous tissue) - were scattered across the melanoma cryosections. These two areas 
clearly differed in the expression of the studied proteins. The overall increasing expression of fibronectin and tenascin $\mathrm{C}$ detected almost exclusively in the fibrous tissue correlated well with the course of SR and the fibrous tissue expansion. On the contrary, very low (locally undetectable) levels of tenascin $\mathrm{C}$ and fibronectin found in melanoma cell areas could be connected with the general loss of the tumour's invasive behaviour $(12,22,27,28,33,34)$. MMP-2, an enzyme degrading ECM proteins, demonstrated increased expression in melanoma cell areas suggesting generalized destruction of melanoma cells and large remodelling of this type of tissue (including its ECM) (35). It is necessary to note that SR of porcine melanoma is not terminated at the 8 months of age because some cancer cells still persist in tumour tissue. On the basis of the gradual destruction of melanoma cells, we can assume a further destruction of resting melanoma cells and continued transformation of melanoma tissue into the fibrous one. These changes will probably proceed for several months and the fibrous tissue will replace the entire melanoma at the end of SR process.

High expression of all three studied proteins in human melanoma is related with cancer phenotype, strong metastatic activity, and worse prognosis $(21,24,36-39)$. An opposite behaviour was observed in the MeLiM melanoma, i.e. low expression of these proteins during the tumour growth phase compared to their overall gradual increase connected with the loss of tumour phenotype and advancing SR. Although SR occurs in human melanoma there are only studies that describe it from the histological and immunological viewpoint but no data are available about the expression of these proteins. Therefore, we are not able to say whether a similar increase in the proteins expression occurs during SR of human melanoma. It may be a reason why some studies suggest a slightly controversial role of these proteins in human melanoma development $(12,40)$ where relatively frequent partial SR may have similar features to complete in the MeLiM animals. Unlike human melanoma, these proteins cannot be used as melanoma markers in the MeLiM model, but they can serve well for monitoring SR.

\section{Conflicts of Interest}

The Authors have no conflict of interest

\section{Acknowledgements}

This study was supported by the Ministry of Education, Youth and Sport of the Czech Republic (the National Sustainability Program project No. LO1609; EXAM - CZ.1.05/2.1.00/03.0124), Czech health research council (AZV project 15-32432A), Czech University of Life Sciences (CIGA 20162001), and RVO 67985904. The Authors would like to thank Dusan Usvald, Luca Vannucci, and Stefan Juhas for tumour and skin excision as well as Jaroslava Sestakova and Jitka Klucinova for technical assistance.

\section{References}

1 Slominski A, Wortsman J, Carlson AJ, Matsuoka LY, Balch CM and Mihm MC: Malignant melanoma. Arch Pathol Lab Med 125: 1295-1306, 2001.

2 Fang L, Lonsdorf AS and Hwang ST: Immunotherapy for advanced melanoma. J Invest Dermatol 128: 2596-25605, 2008.

3 Menzies SW and McCarthy WH: Complete regression of primary cutaneous malignant melanoma. Arch Surg 132: 553556, 1997.

4 Paredes BE: Regression in malignant melanoma. Definition, etiopathogenesis, morphology and differential diagnosis. Pathologe 28: 453-563, 2007.

5 Rambow F, Malek O, Geffrotin C, Leplat JJ, Bouet S, Piton G, Hugot $\mathrm{K}$, Bevilacqua $\mathrm{C}$, Horak $\mathrm{V}$ and Vincent-Naulleau $\mathrm{S}$ : Identification of differentially expressed genes in spontaneously regressing melanoma using the MeLiM swine model. Pigment Cell Melanoma Res 21: 147-161, 2008.

6 Horak V, Fortyn K, Hruban V and Klaudy J: Hereditary melanoblastoma in miniature pigs and its successful therapy by devitalization technique. Cell Mol Biol 45: 1119-1129, 1999.

7 Borovansky J, Horak V, Elleder M, Fortyn K, Smit NP and Kolb AM: Biochemical characterization of a new melanoma modelthe minipig MeLiM strain. Melanoma Res 13: 543-548, 2003.

8 Planska D, Burocziova M, Strnadel J and Horak V: Immunohistochemical analysis of collagen IV and laminin expression in spontaneous melanoma regression in the Melanoma-bearing Libechov Minipig. Acta Histochem Cytochem 48: 15-26, 2015.

9 Levental KR, Yu H, Kass L, Lakins JN, Egeblad M, Erler JT, Fong SF, Csiszar K, Giaccia A, Weninger W, Yamauchi M, Gasser DL and Weaver VM: Matrix crosslinking forces tumor progression by enhancing integrin signaling. Cell 139: 891-906, 2009.

10 Provenzano PP, Eliceiri KW, Campbell JM, Inman DR, White JG and Keely PJ: Collagen reorganization at the tumor-stromal interface facilitates local invasion. BMC Med 4: 38, 2006.

11 Mao Y and Schwarzbauer JE: Fibronectin fibrillogenesis, a cellmediated matrix assembly process. Matrix Biol 24: 389-399, 2005.

12 Kääriäinen E, Nummela P, Soikkeli J, Yin M, Lukk M, Jahkola T, Virolainen S, Ora A, Ukkonen E, Saksela O and Hölttä E: Switch to an invasive growth phase in melanoma is associated with tenascin-C, fibronectin, and procollagen-I forming specific channel structures for invasion. J Pathol 210: 181-191, 2006.

13 Geffrotin C, Garrido JJ, Tremet L and Vaiman M: Distinct tissue distribution in pigs of tenascin- $\mathrm{X}$ and tenascin-C transcripts. Eur J Biochem 231: 83-92, 1995.

14 Matsumoto K, Saga Y, Ikemura T, Sakakura T and ChiquetEhrismann R: The distribution of tenascin- $\mathrm{X}$ is distinct and often reciprocal to that of tenascin-C. J Cell Biol 125: 483-493, 1994.

15 Crossin KL: Tenascin: a multifunctional extracellular matrix protein with a restricted distribution in development and disease. J Cell Biol 61: 592-598, 1996.

16 Jones FS and Jones PL: The tenascin family of ECM glycoproteins: structure, function, and regulation during embryonic development and tissue remodeling. Dev Dyn 218: 235-259, 2000.

17 Sevastre B, van Ederen AM, Terlou M, Gruys E and Nederbragt $\mathrm{H}$ : Immunohistochemical expression of tenascin in melanocytic tumours of dogs. J Comp Pathol 136: 49-56, 2007. 
18 Geffrotin C, Tricaud Y, Crechet F, Castelli M, Lefaix JL and Vaiman M: Unlike tenascin- $X$, tenascin-C is highly up-regulated in pig cutaneous and underlying muscle tissue developing fibrosis after necrosis induced by very high-dose gamma radiation. Rad Res 149: 472-481, 1998.

19 Vollmer G: Biologic and oncologic implications of tenascinC/hexabrachion proteins. Crit Rev Oncol Hematol 25: 187-210, 1997.

20 Takahashi Y, Sawada G, Kurashige J, Matsumura T, Uchi R, Ueo H, Ishibashi M, Takano Y, Akiyoshi S, Iwaya T, Eguchi H, Sudo T, Sugimachi K, Yamamoto H, Doki Y, Mori M and Mimori K: Tumor-derived tenascin-C promotes the epithelial-mesenchymal transition in colorectal cancercells. Anticancer Res 33: 1927-34, 2013.

21 Herlyn M, Graeven U, Speicher D, Sela BA, Bennicelli JL, Kath $\mathrm{R}$ and Guerry $\mathrm{D}$ 4th: Characterization of tenascin secreted by human melanoma cells. Cancer Res 51: 4853-4858, 1991.

22 Hoek K, Rimm DL, Williams KR, Zhao H, Ariyan S, Lin A, Kluger HM, Berger AJ, Cheng E, Trombetta ES, Wu T, Niinobe M, Yoshikawa K, Hannigan GE and Halaban R: Expression profiling reveals novel pathways in the transformation of melanocytes to melanomas. Cancer Res 64: 5270-5282, 2004.

23 Hofmann UB, Westphal JR, Van Muijen GN and Ruiter DJ: Matrix metalloproteinases in human melanoma. J Invest Dermatol 115: 337-344, 2000.

24 Hofmann UB, Houben R, Brocker EB and Becker JC: Role of matrix metalloproteinases in melanoma cell invasion. Biochimie 87: 307-314, 2005

25 Vaisanen A, Kallioinen M, Taskinen PJ and TurpeenniemiHujanen T: Prognostic value of MMP-2 immunoreactive protein (72 kD type IV collagenase) in primary skin melanoma. J Pathol 186: 51-58, 1998.

26 Virga J, Szemcsák CD, Reményi-Puskár J, Tóth J, Hortobágyi T, Csősz É, Zahuczky G, Szivos L, Bognár L and Klekner A: Differences in extracellular matrix composition and its role in invasion in primary and secondary intracerebral malignancies. Anticancer Res 37: 4119-4126, 2017.

27 Gaggioli C, Deckert M, Robert G, Abbe P, Batoz M, Ehrengruber MU, Ortonne JP, Ballotti R and Tartare-Deckert S: HGF induces fibronectin matrix synthesis in melanoma cells through MAP kinase-dependent signaling pathway and induction of Egr-1. Oncogene 24: 1423-1433, 2005.

28 Gaggioli C, Robert G, Bertolotto C, Bailet O, Abbe P, Spadafora A, Bahadoran P, Ortonne JP, Baron V, Ballotti R and TartareDeckert S: Tumor-derived fibronectin is involved in melanoma cell invasion and regulated by V600E B-Raf signaling pathway. J Invest Dermatol 127: 400-410, 2007.

29 Bittner M, Meltzer P, Chen Y, Jiang Y, Seftor E, Hendrix M, Radmacher M, Simon R, Yakhini Z, Ben-Dor A, Sampas N, Dougherty E, Wang E, Marincola F, Gooden C, Lueders J, Glatfelter A, Pollock P, Carpten J, Gillanders E, Leja D, Dietrich K, Beaudry C, Berens M, Alberts D and Sondak V: Molecular classification of cutaneous malignant melanoma by gene expression profiling. Nature 406: 536-540, 2000.
30 Geffrotin C, Horak V, Créchet F, Tricaud Y, Lethias C, VincentNaulleau $\mathrm{S}$ and Vielh P: Opposite regulation of tenascin-C and tenascin- $\mathrm{X}$ in MeLiM swine heritable cutaneous malignant melanoma. Biochim Biophys Acta 1524: 196-202, 2000.

31 Chiquet-Ehrismann $\mathrm{R}$ and Chiquet M: Tenascins: regulation and putative functions during pathological stress. J Pathol 200: 488499, 2003.

32 Cui J, Chen D, Misfeldt ML, Swinfard RW and Bystryn JC: Antimelanoma antibodies in swine with spontaneously regressing melanoma. Pigment Cell Res 8: 60-63, 1995.

33 Adams M, Jones JL, Walker RA, Pringle JH and Bell SC: Changes in tenascin-C isoform expression in invasive and preinvasive breast disease. Cancer Res 62: 3289-3297, 2002.

34 Ioachim E, Charchanti A, Briasoulis E, Karavasilis V, Tsanou H, Arvanitis DL, Agnantis NJ and Pavlidis N: Immunohistochemical expression of extracellular matrix components tenascin, fibronectin, collagen type IV and laminin in breast cancer: their prognostic value and role in tumour invasion and progression. Eur J Cancer 38: 2362-2370, 2002.

35 Chen GS, Lu MP and Wu MT: Differential expression of matrix metalloproteinase-2 by fibroblasts in co-cultures with keratinocytes, basal cell carcinoma and melanoma. J Dermatol 33: 609-615, 2006

36 Clark EA, Golub TR, Lander ES and Hynes RO: Genomic analysis of metastasis reveals an essential role for RhoC. Nature 406: 532-535, 2000

37 Gould Rothberg BE, Bracken MB and Rimm DL: Tissue biomarkers for prognosis in cutaneous melanoma: a systematic review and meta-analysis. J Natl Cancer Inst 101: 452-474, 2009.

38 Rotte A, Martinka M and Li G: MMP2 expression is a prognostic marker for primary melanoma patients. Cell Oncol 35: 207-216, 2012.

39 Ji BC, Hsiao YP, Tsai CH, Chang SJ, Hsu SC, Liu HC, Huang YP, Lien JC and Chung JG: Cantharidin impairs cell migration and invasion of A375.S2 human melanoma cells by suppressing MMP-2 and -9 through PI3K/NF-kB signaling pathways. Anticancer Res 35: 729-738, 2015.

40 Fontaine D, Parkhill W, Greer W and Walsh N: Partial regression of primary cutaneous melanoma: is there an association with sub-clinical sentinel lymph node metastasis? Am J Dermatopathol 25: 371-376, 2003.
Received May 20, 2018

Revised June 15, 2018

Accepted June 18, 2018 